\title{
Relation between circulating sex steroid concentrations and sexual behaviour during pregnancy and post partum in the domestic rabbit
}

\author{
Isabelle Stoufflet and Monique Caillol \\ Unité de Neurobiologie de la Reproduction, Institut National de la Recherche Agronomique, \\ 78350 Jouy-en-Josas, France
}

\begin{abstract}
Summary. Sexual behaviour of 16 female and 12 male rabbits was studied during pregnancy and early post partum. The main behavioural events of the male (nuzzling and mounting) did not differ in the presence of receptive or non-receptive females. When introduced into the cage of the male, receptive and non-receptive females flattened to the floor or circled around. Sexual receptivity to males decreased in early pregnancy and increased to a maximum a few days around parturition; on Days 1 and 6 post partum, all experimental rabbits submitted to mating. Two groups of females were distinguished: one group submitting to mating whatever the stage of pregnancy, the second being receptive only during the few days before parturition or post partum. During pregnancy and early post partum there was no relation between the colour of the vulva and the female sexual behaviour. Does remained sexually receptive even when progesterone concentrations were high. Nevertheless, the number of receptive females was higher when progesterone concentrations decreased around parturition and the mean daily progesterone values were consistently higher in non-receptive than in receptive females. Oestrogen concentrations during pregnancy were very low and were not related to receptive behaviour.
\end{abstract}

Keywords: sexual behaviour; rabbit; pregnancy; post partum; steroid hormones

\section{Introduction}

Rabbit and hare females ovulate in response to copulation. In these 2 lagomorphs, oestrous behaviour has been reported to occur during various physiological situations. In non-pregnant non-pseudopregnant doe rabbits, Moret (1980) observed an alternation of periods of receptivity during which females submitted to mating, followed by periods of non-receptivity. Duration of these periods was variable between females. Cycles of receptivity of 6 or 7 days have been described in confined wild or domestic female rabbits (Myers \& Poole, 1962) and in brown hares (Lepus europaeus) (Caillol \& Martinet, 1979). During pseudopregnancy, receptivity is maintained at a low level in doe rabbits (Hammond \& Marshall, 1925; Caillol et al., 1983) and hares (Caillol \& Martinet, 1979). Hammond \& Marshall (1925), Beyer \& Rivaud (1969) and Moret (1980) have reported that the domestic rabbit remains receptive during pregnancy but that sexual receptivity to males decreases at the beginning of pregnancy and increases just before parturition. A similar variation in sexual receptivity was observed in pregnant hares (Martinet et al., 1970).

Sexual receptivity can be induced in ovariectomized rabbits by oestrogens (McDonald et al., 1970) and aromatizable androgens (Beyer et al., 1970) while progesterone inhibits this behaviour (Beyer \& McDonald, 1973; Elsaesser, 1980). 
Nevertheless, during pseudopregnancy, as during pregnancy, receptivity is maintained although progesterone concentrations are high. To our knowledge, no data concerning sexual behaviour of pregnant rabbits in relation to the concentrations of circulating steroids are available. We have therefore studied the sexual behaviour of male and female rabbits during pregnancy and early post partum in relation to circulating steroid concentrations.

\section{Materials and Methods}

Animals. Sixteen nulliparous New Zealand White female rabbits, $>6$ months of age, were used. The day of mating with known fertile bucks was designated as Day 0 of pregnancy. Twelve sexually experienced male rabbits were used for behavioural tests. The animals were housed in individual cages, fed commercial pellets and given water ad libitum.

Behavioural tests. The 16 females were presented to 3 different males on 4 days/week from Day 6 to Day 27 of pregnancy and then every day until Day 6 post partum. The female was introduced into the male's cage for $1 \mathrm{~min}$. Durations of the behaviours observed in the male and the female were determined using a stopwatch. For the male, 3 behavioural events were recorded: inactivity, nuzzling the female and mounting. The female showed different sexual behaviours during a test: flattening to the floor in a corner of the cage, circling around the cage, mounting the male, lordosis and submission to mating, and vocalization. If the female submitted to mating, she was removed and not presented to other males that day. Before testing, the colour of the vulva was noted. Four colours were distinguished: white, pink, red and purple. After testing, $5 \mathrm{ml}$ blood were collected by cardiac puncture and kept at ambient temperature for $30 \mathrm{~min}$. Serum was separated by centrifugation $(5000 \mathrm{~g})$ at $4^{\circ} \mathrm{C}$ and frozen until assay.

Steroid assays. Using specific radioimmunoassays, the concentrations of progesterone, oestrone and oestradiol$17 \beta$ in each serum sample were determined. Non-radioactive steroids were purchased from Steraloids (Wilton, NH 03086, U.S.A.); radioactive steroids were obtained from the Radiochemical Centre (Amersham, Buckinghamshire, U.K.) and C.E.A. (Saclay, France). Merck analytical grade solvents were used without re-distillation. Before extraction, radioactive steroids $(500$ c.p.m.) were added to calculate recovery. Progesterone was measured after hexane extraction of $1 \mathrm{ml}$ serum. Oestrogens were extracted from $1 \mathrm{ml}$ serum by diethyl ether and purified on Sephadex LH20 microcolumns (height $5 \mathrm{~cm}$; benzene-ethanol $(85 / 15, \mathrm{v} / \mathrm{v})$ as eluant) according to Castanier \& Scholler (1970). The different fractions were then dried and steroids were dissolved in phosphate buffer $(\mathrm{pH} 7 \cdot 25)$. Recovery was determined in an aliquant; 2 samples of $0.1 \mathrm{ml}$ were incubated at $4^{\circ} \mathrm{C}$ with the diluted antiserum for $3 \mathrm{~h}$ and for $2 \mathrm{~h}$ more with the radioactive steroid ( 4000 c.p.m.). Bound and free fractions were separated by a dextran-charcoal mixture. The blank values, run with each assay, were below assay sensitivity. The mean reliability criteria of these assays are shown in Table 1.

Statistical analysis. The percentages of animals showing a behaviour during pregnancy were compared by $\chi^{2}$ tests. Mean \pm s.e.m. values were calculated for the duration of behavioural events and the serum steroid concentrations. For each stage of pregnancy and the post-partum period, the data observed for receptive and non-receptive females were compared by the analysis of variance. Statistical differences were postulated for $P<0.05$.

Table 1. Reliability criteria of the progesterone, oestrone and oestradiol-17 $\beta$ radioimmunoassays

\begin{tabular}{|c|c|c|c|c|c|c|c|}
\hline \multirow[b]{3}{*}{ Steroid } & \multirow[b]{3}{*}{ Antibody } & \multirow[b]{3}{*}{$\begin{array}{c}\text { Cross-reaction } \\
(\%)\end{array}$} & \multirow{3}{*}{$\begin{array}{c}\text { Recovery } \\
\text { after } \\
\text { extraction } \\
\text { and chroma- } \\
\text { tography (\%) }\end{array}$} & \multirow{2}{*}{\multicolumn{2}{|c|}{$\begin{array}{c}\text { Sensitivity } \\
\text { Standard } \\
\text { assay curve }\end{array}$}} & \multirow{2}{*}{\multicolumn{2}{|c|}{ Precision $(\%)$}} \\
\hline & & & & & & & \\
\hline & & & & $\mathrm{pg}$ & $\mathrm{pg} / \mathrm{ml}$ & $\begin{array}{l}\text { Intra- } \\
\text { assay }\end{array}$ & $\begin{array}{l}\text { Inter- } \\
\text { assay }\end{array}$ \\
\hline Progesterone & $\begin{array}{l}\text { Progesterone-1 l } \alpha \\
\text { hemisuccinate-- } \\
\text { BSA }\end{array}$ & $\begin{array}{l}5 \alpha \text {-Pregnane-3,20- } \\
\text { dione }=7.5 \\
\text { Deoxycorticosterone } \\
\quad=7.5\end{array}$ & $64-97$ & 5 & 50 & $3 \cdot 6$ & $8 \cdot 5$ \\
\hline Oestrone & $\begin{array}{l}\text { Oestrone-17 } \beta \text { - } \\
\text { para-amino- } \\
\text { benzoic-BSA }\end{array}$ & $\begin{array}{l}\text { 16-Hydroxy-oestrone } \\
\quad=3.6 \\
\text { Oestradiol-17 } \beta=1.9\end{array}$ & $56-90$ & 5 & 15 & $2 \cdot 7$ & $6 \cdot 9$ \\
\hline $\begin{array}{l}\text { Oestradiol- } \\
17 \beta\end{array}$ & $\begin{array}{l}\text { Oestradiol-17及 } \\
\text { 7-carboxy-methyl- } \\
\text { oxime-BSA }\end{array}$ & $\begin{array}{l}\text { Oestriol }=1.8 \\
\text { Oestrone }=1.0\end{array}$ & $59-85$ & 5 & 15 & $2 \cdot 4$ & $10 \cdot 3$ \\
\hline
\end{tabular}




\section{Results}

\section{Sexual behaviour}

Description of events. After introduction of a female into the male's cage, the male began to nuzzle her around the genital area and behind the ears or tried to mount her. Sometimes, he remained completely inactive and seemed not to be interested at all by the female. If the female submitted to mating, she took the position of lordosis and copulation occurred rapidly followed by a backward lunge of the male away from the female. If the female did not submit to mating, she flattened on the floor in a corner of the cage; then the male could nuzzle her, scratch the female's back with his forelegs or beat her ears. The female could try to run from the male and circle around and, sometimes, tried to mount the male. Some doe rabbits vocalized during the test.

Sexual behaviour of the male. In the presence of pregnant females, the male remained inactive for a very short time during a test $(<10 \mathrm{sec})$. Duration of nuzzling and mounting behaviours did not differ except on Days 20-23 of pregnancy; at this stage of pregnancy, the female was nuzzled longer $(43.3 \pm 3.2 \mathrm{sec})$ than mounted $(13.7 \pm 1.1 \mathrm{sec})(P<0.01)$. Nevertheless, there was no significant variation in the male sexual behaviour according to the physiological stage of the female $(P>0.05)$. The sexual behaviour of male rabbits in the presence of receptive or non-receptive does significantly differed at the beginning of pregnancy (Days 6-16): non-receptive females were nuzzled less $(26.7 \pm 1.1$ compared with $44.0 \pm 3.9 \mathrm{sec})$ and mounted for longer $(29.4 \pm 1.9$ compared with $5.13 \pm 1.9 \mathrm{sec})$ than were receptive females during the tests preceding lordosis $(P<0.005)$ (Figs $1 \mathrm{a}, \mathrm{b})$. Later, in the second part of pregnancy and during the post-partum period, the male sexual behaviour was similar in the presence of receptive and non-receptive females.

Sexual behaviour of the female. In most tests, pregnant females alternately flattened and circled round the cage. During $20 \%$ of tests, pregnant females remained flattened in a corner of the cage. Circling during the whole test occurred only at the beginning of pregnancy and post partum. However, no significant variation in the sexual behaviour of pregnant females could be observed $(P>0.05)$. Comparison of the behaviour events of receptive and non-receptive females showed differences only in the first part of pregnancy (Days 6-16): the proportion of tests during which the female remained flattened was higher $(P<0.005)$ in non-receptive females $(49 \%)$ than in receptive

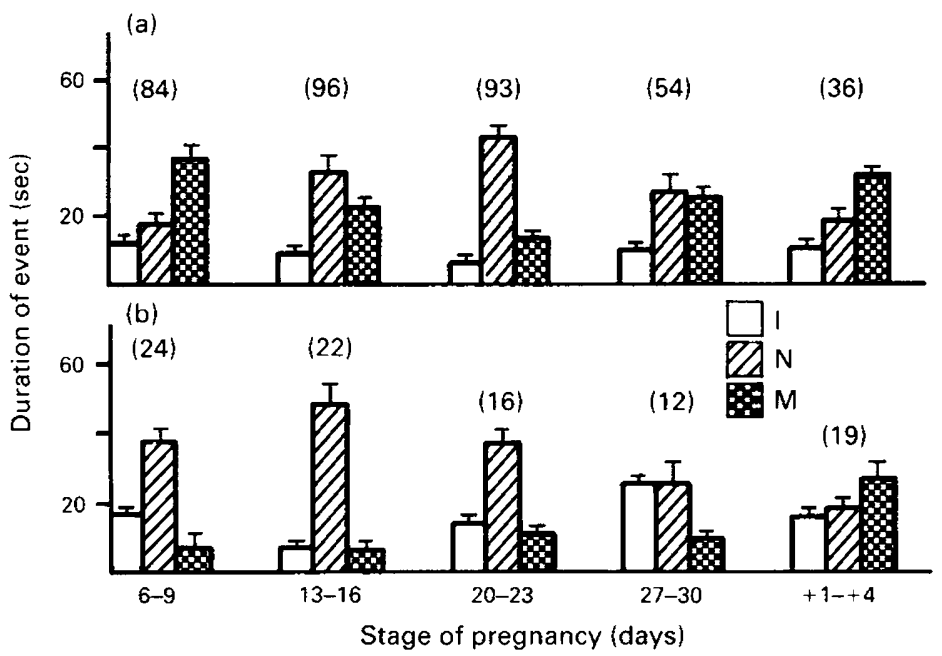

Fig. 1. Changes in sexual behaviour of male rabbits in the presence of non-receptive pregnant females (a) and receptive pregnant females (b). $\mathrm{I}=$ inactivity; $\mathrm{N}=$ nuzzling; $\mathbf{M}=$ mounting. Values are mean \pm s.e.m. for the no. of observations indicated. 


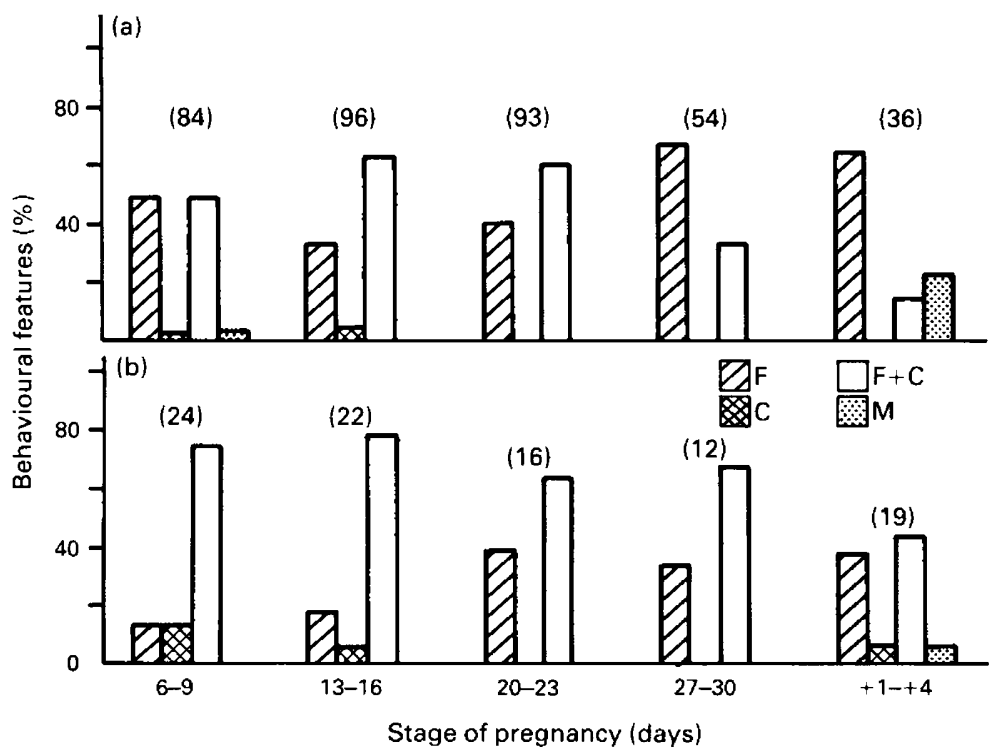

Fig. 2. Changes of sexual behaviour in (a) non-receptive pregnant female and (b) receptive pregnant female rabbits. $\mathrm{F}=$ flattening during $1 \mathrm{~min} ; \mathrm{C}=$ circling during $1 \mathrm{~min} ; \mathrm{F}+\mathrm{C}=$ flattening + circling; $M=$ mounting the male. The no. of observations is given in parentheses.

females (13\%) and the females displaying both types of behaviour (flattening and circling) during a test remained 'flattened' longer when they were non-receptive $(37.3 \pm 1.9 \mathrm{sec})$ than when they were receptive $(27.5 \pm 3.3 \mathrm{sec})(P<0.005)$ (Figs $2 \mathrm{a}, \mathrm{b})$. However, these differences disappeared during the second part of pregnancy. During the behavioural tests, some females vocalized in a sporadic or continuous manner. No significant differences in the occurrence of this behaviour were found between receptive and non-receptive females. Females mounted the male in only 12 tests: 1 on Day 6 and the others after parturition. This behaviour was followed by mating on only 6 occasions.

Whatever the stage of pregnancy, $67 \%$ of matings occurred within $20 \mathrm{sec}$ after introduction of the female into the male's cage, $23 \%$ of matings occurred between 20 and $40 \mathrm{sec}$ and $10 \%$ between 40 and $60 \mathrm{sec}$ (Fig. 3a). At the beginning of pregnancy, females accepted more often the second or the third male presented. The proportion of females which displayed lordosis with the first male presented increased to a maximum $(85 \%)$ on Days $31 \pm 1(P<0.005)$. In the early post-partum period, this percentage decreased to $33 \%$ (Fig. 3b).

The proportion of receptive females remained below 50\% from Days 6 to 23 of pregnancy then increased and reached $100 \%$ at parturition. During the first days post partum, $70 \%$ of females submitted to mating, all females being receptive on Days 1 and 6 post partum. Some females refused the male during the whole pregnancy while the others submitted to mating whatever the stage of pregnancy and during variable periods of time. Among the 16 experimental females, 8 accepted the male in a sporadic or continuous manner and 5 aborted between Day 24 and 28 . Five females submitted to mating only a few days before parturition and 2 refused the male during the whole of pregnancy and were mated only post partum (Fig. 4). Parturition occurred on Day 31 in 9 females and on Day 30 in the other one. Litter size was $8 \cdot 3 \pm 1 \cdot 6$ (range 5-11) and there was no correlation between the number of young born and the sexual behaviour of the female.

Females with a white vulva were only noted in early pregnancy and after parturition. The proportion of females with a pink vulva remained high during pregnancy $(72 \%)$ then decreased at parturition while the proportion of females with a purple vulva was maximum. A red vulva was 

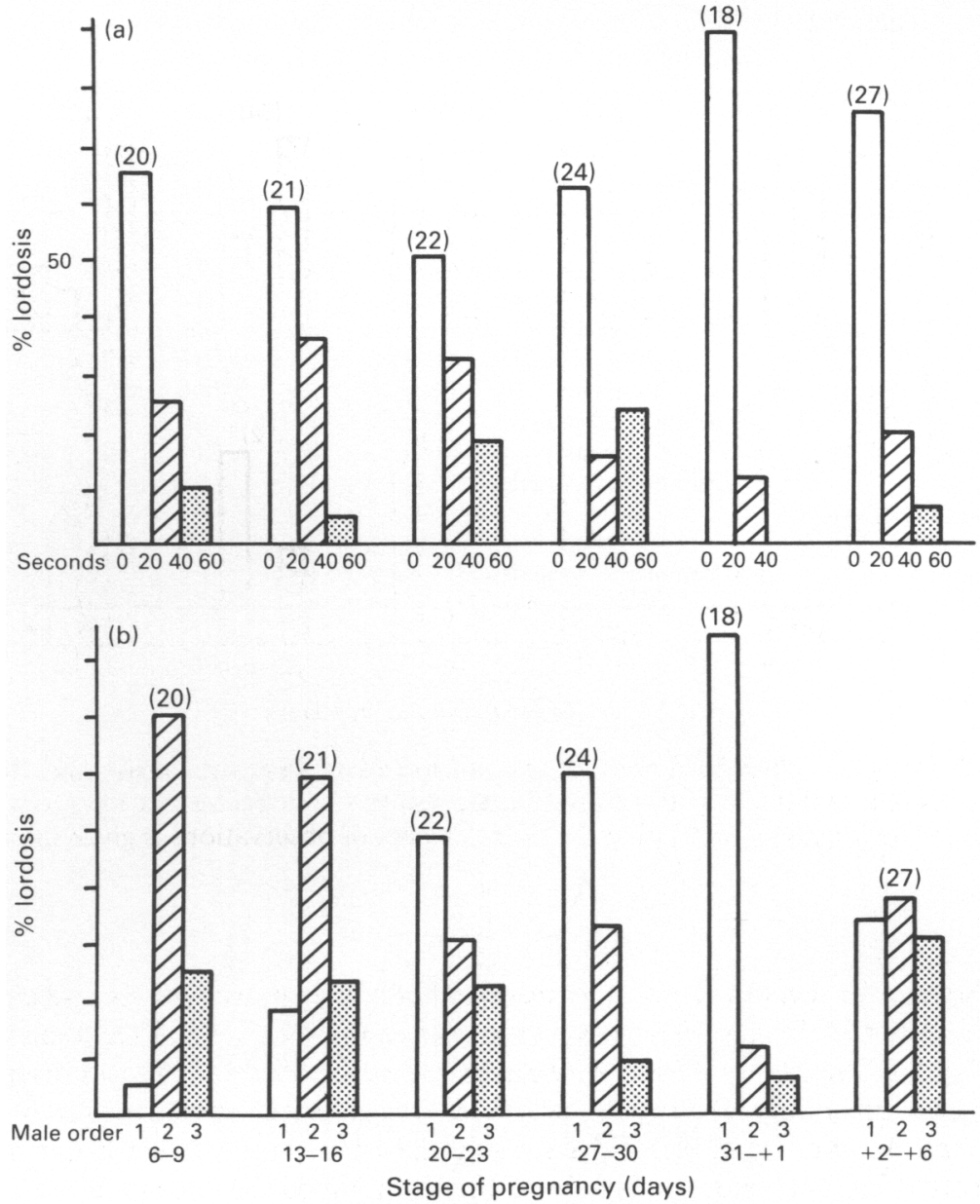

Fig. 3. Lordosis in female rabbits: (a) latency to and (b) in relation to the order of presentation of the accepted male. The numbers of observations are given in parentheses.

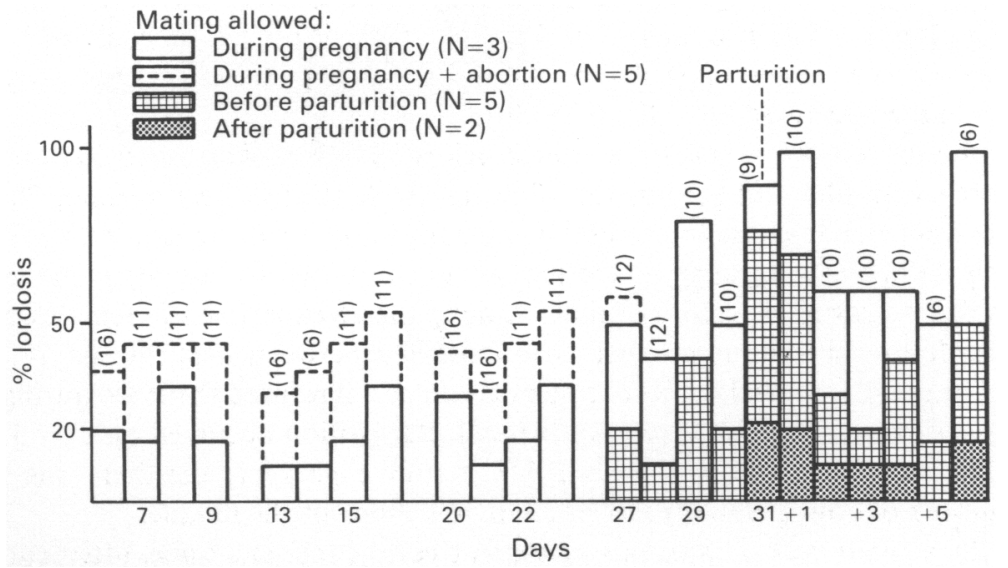

Fig. 4. Changes of the proportion of females allowing mating from Day 6 of pregnancy to Day 6 post partum. The no. of females tested on each day is given in parentheses. 
Table 2. Vulva coloration of female rabbits during pregnancy and early post partum and the numbers submitting to males

\begin{tabular}{llrrrr}
\hline & & \multicolumn{4}{c}{ Vulva coloration } \\
\cline { 3 - 6 } Days & No. of females & White & Pink & Red & Purple \\
\hline Pregnant & & & & & \\
$6-9$ & In group & 1 & 43 & 0 & 1 \\
& Submitting to male & 0 & 21 & 0 & 0 \\
$13-16$ & $\quad$ In group & 5 & 40 & 4 & 1 \\
& Submitting to male & 3 & 17 & 0 & 1 \\
$20-23$ & $\quad$ In group & 0 & 32 & 10 & 8 \\
& Submitting to male & 0 & 19 & 1 & 2 \\
$27-31$ & $\quad$ In group & 0 & 23 & 13 & 17 \\
& Submitting to male & 0 & 16 & 5 & 13 \\
Post partum & $\quad$ In group & 10 & 29 & 2 & 11 \\
$+1-+4$ & Submitting to male & 8 & 16 & 1 & 9 \\
& &
\end{tabular}

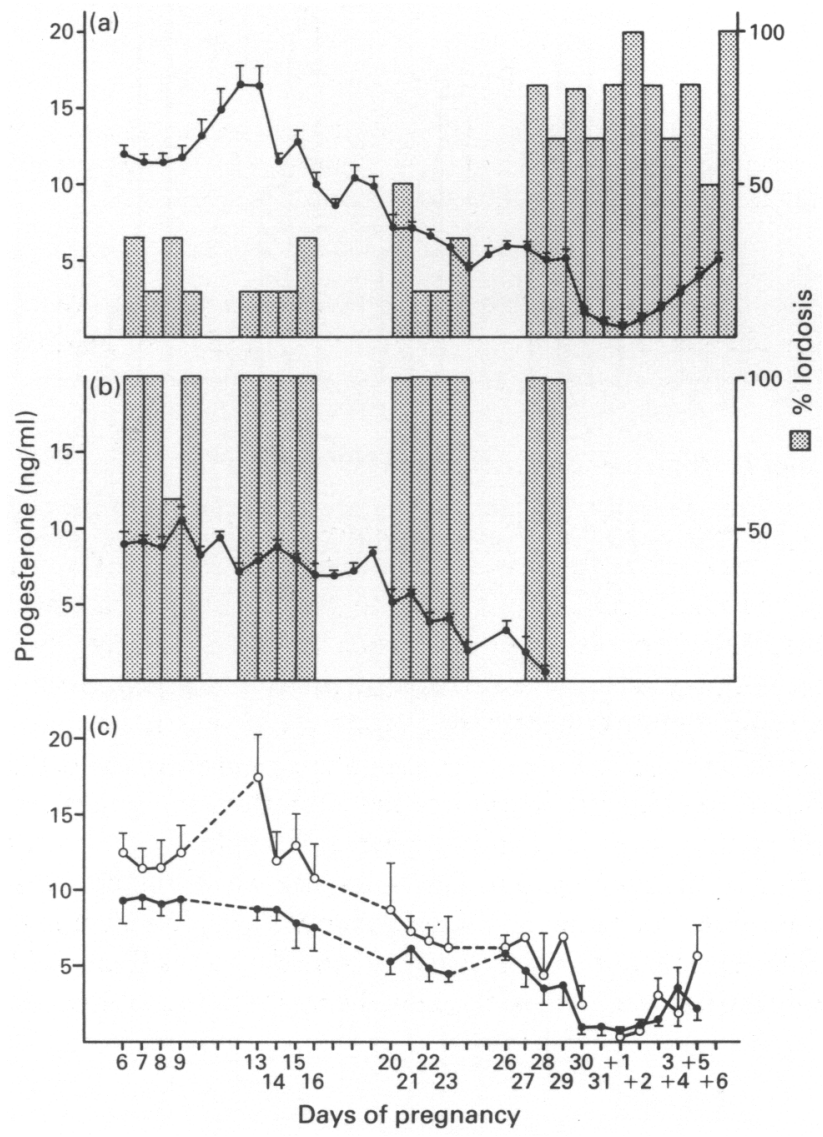

Fig. 5. Patterns of circulating progesterone concentrations (mean \pm s.e.m.) in (a) 6 pregnant females, (b) 4 pregnant females which aborted, and (c) receptive (- $)$ and non-receptive $(\mathrm{O}-\mathrm{O})$ pregnant females. The receptivity of pregnant females is shown by histograms. 


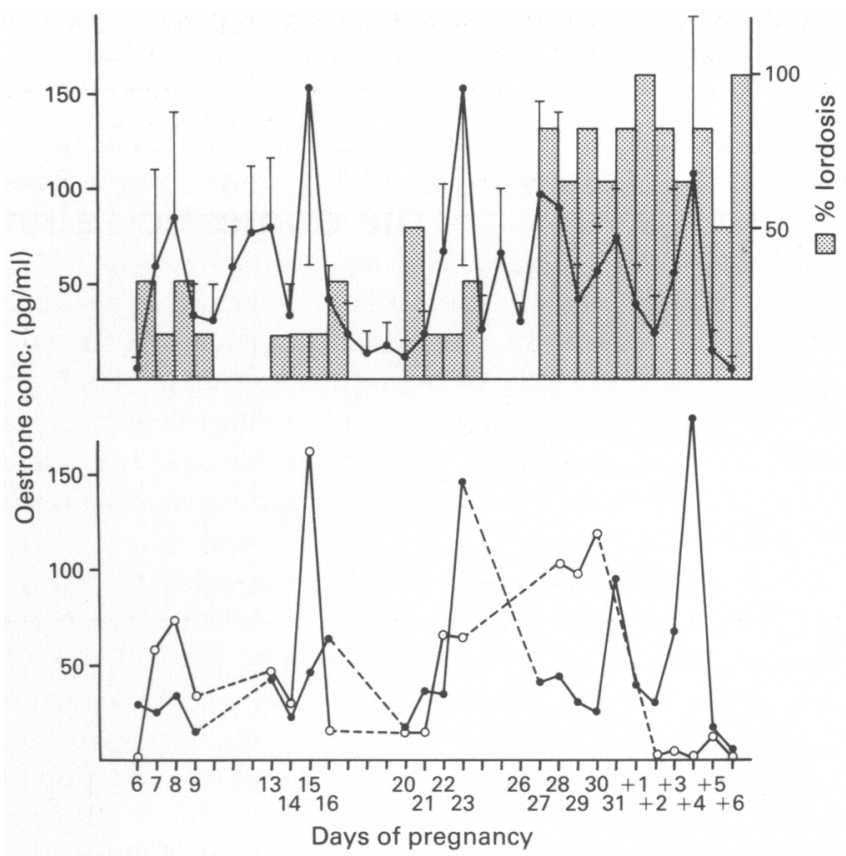

Fig. 6. Patterns of circulating oestrone concentrations (mean \pm s.e.m.) in (a) 6 pregnant females and (b) receptive $\left(O_{-}\right)$and non-receptive $(\mathrm{O}-\mathrm{O})$ pregnant females. The receptivity of pregnant females is shown by histograms.

observed in a small number of pregnant rabbits. During pregnancy and early post partum, females submitted to mating whatever the colour of the vulva (Table 2). No relationship between female sexual receptivity and colour of the vulva could be observed.

\section{Serum progesterone and oestrogen concentrations}

Mean progesterone concentrations of 6 pregnant rabbits rose from Day 6 of pregnancy $(12.2 \pm 0.6 \mathrm{ng} / \mathrm{ml})$ to a maximum on Days $12-13(16.5 \pm 1 \cdot 1 \mathrm{ng} / \mathrm{ml})$. They then decreased slowly until Day $29(5.4 \pm 0.5 \mathrm{ng} / \mathrm{ml})$ and more rapidly to reach a minimum the day after parturition $(0 \cdot 8 \pm 0 \cdot 1 \mathrm{ng} / \mathrm{ml}$ ) (Fig. $5 \mathrm{a})$. The rise in progesterone after parturition could correspond to the establishment of a pseudopregnancy or a second pregnancy. The proportion of receptive females was maximum when progesterone concentrations were the lowest, i.e. at parturition (Fig. 5a). The 4 females which aborted showed lower progesterone concentrations and the peak value at midpregnancy was not observed (Fig. 5b). These females submitted to mating even at the beginning of pregnancy. During pregnancy, the mean daily progesterone values were consistently higher in nonreceptive than in receptive females (Fig. 5c). The difference was significant on Day $13(P<0.025)$.

The concentrations of oestrone and oestradiol remained very low during pregnancy. Oestradiol was always almost undetectable and mean oestrone concentrations fluctuated from 5 to $150 \mathrm{pg} / \mathrm{ml}$ (Fig. 6a). No relationship between female sexual behaviour and oestrogen concentrations was observed (Fig. 6b).

\section{Discussion}

The results reported in the present study constitute the first quantitative analysis of the sexual behaviour of male and female rabbits during pregnancy. Many of the behavioural events which 
have been reported for wild rabbits are also observed in domestic rabbits. However, few data are available on the sexual behaviour of the male rabbit. Southern (1947) and Worden \& Leahy (1962) have identified different sexual behaviours in the confined wild rabbit: courtship chasing (sexual following, circling and jumping), tail 'flagging', enurination and copulatory behaviour. Similar behavioural events have been observed by Heath (1972) for domestic rabbits. In our study, the males displayed 2 important behaviours, nuzzling and mounting, and remained inactive for a short time during the tests. A quantitative difference in male behaviour was noted in the presence of receptive or non-receptive females only in the first part of pregnancy. The domestic rabbit has been reported to use a variety of scent-marking behaviours. A territorial function for chin-marking was first described by Mykytowycz (1968) for the wild male rabbit. Heath (1972) has noted that domestic bucks marked a variety of inanimate objects as well as the females in this manner. This particular behaviour has not been observed in our study, perhaps because the tests were performed in the male's cage, i.e. in his own territory. Furthermore, the experienced males used in this study were trained to mount the females.

When introduced into the male's cage, the pregnant doe rabbit displays 2 main behaviours: flattening in the corner of the cage and/or circling away from the male. These sexual behaviours have been described by Heath (1972) for domestic female rabbits. The difference between a receptive and a non-receptive female is not easy to establish in the rabbit. As for the male, a quantitative difference of behaviour was observed between receptive and non-receptive females only in the first part of pregnancy during which flattening could be considered as a criterion of non-receptivity as described by Caillol et al. (1983) in pseudopregnant domestic rabbits. During the second part of pregnancy, no difference was noted between sexual behaviour of receptive and non-receptive females. This could be due to a reduced mobility of the female at the end of pregnancy. Mounting the male was only observed post partum and seemed to be inhibited during pregnancy as described by Beyer \& McDonald (1973). In our study, this event was not always followed by submission to mating in contrast to what has been reported by Hammond \& Marshall (1925) and Yaschine et al. (1967) for non-pregnant non-pseudopregnant rabbits and by Caillol et al. (1983) for pseudopregnant rabbits. In the female rabbit, mounting depends on ovarian secretions since ovariectomy sharply decreases this activity (Yaschine et al., 1967) and androgen is much more effective than oestrogen in restoring this particular behavioural feature (Soto et al., 1985). Vocalizations seemed to be a characteristic of each female and there was no relationship between this event and sexual receptivity during pregnancy or pseudopregnancy (Caillol et al., 1983).

The doe rabbit could use chin-marking behaviour to communicate reproductive status to males. Soares \& Diamond (1982) have shown that female rabbits exhibit decreased chin-marking during pregnancy and no female observed in our study displayed this activity, even during the post-partum period. Our experimental conditions did not permit observation of this chin-marking behaviour in males or in females. Vulva coloration varied during pregnancy, a white vulva occurring only in early pregnancy and after parturition and the proportion of rabbits with a purple vulva rising on Days 27-31. There was no relationship between the colour of the vulva and the incidence of lordosis in pregnant rabbits, although a red vulva is considered as an indication of receptivity in nulliparous females (Lefevre \& Moret, 1978), after pregnancy or pseudopregnancy (Friedman, 1938) and during pseudopregnancy (Caillol et al., 1983).

The pattern of female sexual behaviour varied during pregnancy. In early pregnancy, female receptivity decreased but was augmented a few days before parturition. These results confirm the observations of Hammond \& Marshall (1925), Beyer \& Rivaud (1969) and Moret (1980). All females submitted to mating on Days 1 and 6 post partum. Beyer \& Rivaud (1969) have shown that all females were receptive the day after parturition; Osteen \& Mills (1980) reported reappearance of large, steroidogenically active follicles in the ovary on Day 6 of pseudopregnancy and Myers \& Poole (1962) described a 6-7-day cycle of sexual attractivity in pseudopregnant domestic rabbits. Among the experimental rabbits, 2 groups of females could be distinguished: some females submitted to mating whatever the stage of pregnancy, the others were receptive in the few days 
before parturition or in the post-partum period only. These different groups of females have been described for non-pregnant non-pseudopregnant females (Moret, 1980) and for pseudopregnant females (Caillol et al., 1983): some females always accepted the male while the others accepted the male only sporadically.

The mean peripheral serum concentrations of progesterone described in the present study are similar to those previously reported for pregnant rabbits (Challis et al., 1973; Baldwin \& Stabenfeldt, 1974; Browning et al., 1980; Lau et al., 1982). The highest mean concentration of circulating progesterone was observed around Days 12-13 followed by a gradual decline between mid-pregnancy and parturition. A relationship between circulating progesterone concentrations and sexual behaviour was established: the number of receptive females was higher when progesterone values decreased, i.e. in late pregnancy. However, doe rabbits remained sexually receptive even when progesterone concentrations were high but non-receptive females exhibited consistently higher values than did receptive ones. Progesterone therefore seems to inhibit sexual receptivity as described by Beyer \& McDonald (1973), while no characteristic progesterone concentration corresponding to a receptivity level could be determined. Circulating concentrations of oestrogens remained very low and did not show a marked variation during pregnancy as noted by Lau et al. (1982). The mean concentration of oestrone was slightly higher than that of oestradiol. We have not observed at parturition the peak value of oestrogens described by Challis et al. (1973). Circulating oestrogen values were too low and variable between females to be clearly related to sexual behaviour. However, injections of aromatizable androgens or oestrogens induce oestrous behaviour in ovariectomized rabbits (Beyer et al., 1970) and Elsaesser (1980) has shown that oestrogens are necessary for receptivity in the female rabbit.

Elevated circulating concentrations of progesterone, characteristic of pregnancy, do not inhibit sexual behaviour in all rabbits. Nevertheless these high progesterone values are responsible for the fact that these matings do not lead to gonadotrophin release and ovulation during pregnancy (Mills \& Gerardot, 1984). In another induced ovulator, the brown hare, fertile matings are recorded at the end of pregnancy, leading to an ovulation and a natural superfetation (Caillol \& Martinet, 1983). In the rabbit, however, the coitus-induced ovulation is blocked during pregnancy.

We thank Dr J. Fèvre (I.N.R.A., Jouy-en-Josas) for the gift of progesterone antibody; RousselUclaf (France) for oestrogen antibodies; B. Rossano for technical assistance; and A. Solari for statistical analysis of the results.

\section{References}

Baldwin, M.D. \& Stabenfeldt, G.H. (1974) Plasma levels of progesterone cortisol and corticosterone in the pregnant rabbit. Biol. Reprod. 10, 495-501.

Beyer, C. \& McDonald, P. (1973) Hormonal control of sexual behaviour in the female rabbit. Adv. Reprod. Physiol. 6, 185-214.

Beyer, C. \& Rivaud, N. (1969) Sexual behaviour in pregnant and lactating domestic rabbits. Physiol. Behav. 4, 753-757.

Beyer, C., Vidal, N. \& Mijares, A. (1970) Probable role of aromatization in the induction of oestrous behaviour by androgens in the ovariectomized rabbit. Endocrinology 87, 1386-1389.

Browning, J.Y., Landis-Keyes, P. \& Wolf, R.C. (1980) Comparison of serum progesterone, 20 $\alpha$ dihydroprogesterone and estradiol-17 $\beta$ in pregnant and pseudopregnant rabbits: evidence of postimplantation recognition of pregnancy. Biol. Reprod. $23,1014-1019$.
Caillol, M. Martinet, L. (1979) Estrous behavior, follicular growth and pattern of circulating sex steroids during pregnancy and pseudopregnancy in the captive brown hare. Proc. Wld Lagomorph Conf., Guelph, pp. 142-154. Ed. K. Myers. University of Guelph.

Caillol, M. \& Martinet, L. (1983) Mating periods and fertility in the doe hare (Lepus europaeus) bred in captivity. Acta zool. Fennica 174, 65-68.

Caillol, M., Dauphin-Villemant, C. \& Martinet, L. (1983) Oestrous behaviour and circulating progesterone and oestrogen levels during pseudopregnancy in the domestic rabbit. J. Reprod. Fert. 69, 179-186.

Castanier, M. \& Scholler, R. (1970) Dosage radioimmunologique de l'oestrone et de l'oestradiol-17 $\beta$ plasmatiques. C. r, hebd. Séanc. Acad. Sci. Paris, D 271, 1787-1789.

Challis, J.R.G., Davies, I.J. \& Ryan, K.J. (1973) The relationship between progesterone and prostaglandin 
F concentrations in the plasma of pregnant rabbits. Prostaglandins 4, 509-516.

Elsaesser, F. (1980) Effects of active immunization against oestradiol-17\%, testosterone or progesterone on receptivity in the female rabbit and evaluation of specificity. J. Reprod. Fert. 58, 213-218.

Friedman, M. (1938) Criteria for the selection of estrous rabbits. Endocrinology 22, 354-359.

Hammond, J. \& Marshall, F. (1925) Reproduction in the Rabbit. Oliver \& Boyd, Edinburgh.

Heath, E. (1972) Sexual and related territorial behaviour in the laboratory rabbit (Oryctolagus cuniculus). Lab. Anim. Sci. 22, 684691.

Lau, I.F., Saksena, S.K. \& Salmonsen, R. (1982) The concentration of progesterone, $20 \alpha$-dihydroprogesterone, tetosterone, oestrone and oestradiol-17 $\beta$ in serum, amniotic fluid and placental tissue of pregnant rabbits. Acta endocr., Copenh. 99, 605-611.

Lefevre, B. \& Moret, B. (1978) Influence d'une modification brutale de l'environnement sur l'apparition de l'oestrus chez la lapine nullipare. Annls Biol. anim. Biochim. Biophys. 18, 695-698.

Martinet, L., Llegouis, J.J. \& Moret, B. (1970) Quelques observations sur la reproduction du lièvre (Lepus europaeus) en captivité. Annls Biol. anim. Biochim. Biophys. 10, 195-202.

McDonald, P., Vidal, N. \& Beyer, C. (1970) Sexual behaviour in the ovariectomized rabbit after treatment with different amounts of gonadal hormones. Horm. Behav. 1, 161-172.

Mills, T.M. \& Gerardot, R.J. (1984) Dissociation of copulation from ovulation in pregnant rabbits. Biol. Reprod. 30, 1243-1252.
Moret, B. (1980) Comportement d'oestrus chez la lapine. Cuniculture 33, 159-161.

Myers, K. \& Poole, W.E. (1962) Oestrous behaviour cycles in the rabbit, Oryctolagus cuniculus. Nature, Lond. 195, 358-359.

Mykytowycz, R. (1968) Territorial marking by rabbits. Scient. Am. 218, 116-126.

Osteen, G.K. \& Mills, T.M. (1980) Changes in the size, distribution and steroid content of rabbit ovarian follicles during early pseudopregnancy. Biol. Reprod. 22, 1040-1046.

Soares, M.J. \& Diamond, M. (1982) Pregnancy and chin marking in the rabbit, Oryctolagus cuniculus. Anim. Behav. 30, 941-943.

Soto, M.A., Reynoso, M. \& Beyer, C. (1985) Sexual dimorphism in the motor mounting pattern of the New Zealand White rabbit: steroid regulation of vigor and rhythmicity of pelvic thrusting. Horm. Behav. 18, 225-234.

Southern, H.N. (1947) Sexual and aggressive behaviour in the wild rabbit. Behaviour 48, 173-193.

Worden, A.N. \& Leahy, J.S. (1962) The behaviour of rabbits. In Behaviour of Domestic Animals, pp. 397-414. Ed. E. S. E. Hafex. Baillière, Tindal \& Cox, London.

Yaschine, T., Mena, F. \& Beyer, C. (1967) Gonadal hormones and mounting behavior in the female rabbit. Am. J. Physiol. 213, 867-872.

Received 27 April 1987 